\title{
Knowledge of pregnant women about venous thromboembolism
}

\author{
Małgorzata Dybowska', Marta Michalina Zagroba², Monika Szturmowicz', \\ Małgorzata Sobiecka', Katarzyna Lewandowska', Adam Jóźwik ${ }^{3}$, Witold Tomkowski' \\ 'Institute of Tuberculosis and Lung Diseases, Warsaw, Poland \\ ${ }^{2}$ The State Higher Vocational School, Faculty of Health Protection and Humanities, Ciechanów, Poland \\ ${ }^{3}$ Faculty of Physics and Applied Informatics, Department of Computer Science, University of Lodz, Poland
}

\begin{abstract}
Introduction: Venous thromboembolism occurs ten times more often among pregnant women compared to non-pregnant ones. Pulmonary embolism remains the leading cause of death in pregnancy and puerperium. The aim of the study was to investigate knowledge of pregnant or puerperal women about venous thromboembolism.

Material and methods: The study was conducted from October 2017 to January 2018 in a group of 204 women. The diagnostic survey method was applied with the use of a self-designed questionnaire. The survey was conducted using Google Form.

Results: Knowledge of venous thromboembolism was confirmed by less than $40.0 \%$ [CI 33.7, 47.0] of respondents. Less than a quarter of them received the information about the risk of pregnancy-related VTE from medical personnel, about 30\% - from the Internet. Over 20\% [CI 15.2, 26. I] admitted that they did not know any symptoms of this disease.

Conclusions: The survey showed marked deficiencies in knowledge concerning symptoms, risk factors and prevention of VTE among pregnant women. Therefore a special emphasis should be placed on education provided by medical staff in this group of patients.
\end{abstract}

Key words: venous thromboembolism, thrombosis in pregnancy

Acta Angiol 2021; 27, I: 10-16

\section{Introduction}

Pulmonary embolism is the leading cause of death among pregnant and puerperal women $[1-5]$. The incidence of venous thromboembolic disease (VTE) among pregnant women is much higher than in a comparable non-pregnant age group [I-7].

The risk of VTE covers the whole period of pregnancy; however, $40 \%$ of episodes occur in the first trimester, especially in the case of in vitro fertilization [6-10]. The risk of pulmonary embolism is also increased in the postpartum period, especially after caesarean section $[2,5,1 \mathrm{I}]$. Despite the decrease in the number of thromboembolic complications resulting from the fast mobilization of women after childbirth and their early return home, pulmonary embolism remains the main cause of death of women during pregnancy and confinement in developing countries [1-6].

The most common symptoms suggestive of deep vein thrombosis include [5, 12-14]: pain, swelling of the lower leg with a difference in their circumferences above $2 \mathrm{~cm}$, tenderness or pain in the limb, excessive limb warm-up, redness of the skin, widespread superficial veins, subfebrile state, and — less frequently — fever. 
Pulmonary embolism should be suspected if there is: dyspnoea, tachypnoea, pleural chest pain (worsening during inspiration), coronary pain, haemoptysis or fainting [5, 12-14].

Nevertheless, the disease may be asymptomatic or oligosymptomatic in up to $70 \%$ of patients. Moreover, in the case of pregnant women, the diagnosis of VTE is more difficult, because symptoms such as calf oedema and dyspnoea may also occur in the course of normal pregnancy [5, 12-14].

Each woman planning or being at an early stage of pregnancy should be assessed for VTE risk factors $[2, \mathrm{I} I]$ (Table I) and then qualified for one of three risk groups for the disease: high, moderate or low (Table 2).

Appropriate preventive measures should be used depending on the predicted risk of VTE [2, II].

Prophylaxis of venous thromboembolism may be primary - before the occurrence of a VTE episode, or secondary - after diagnosis of VTE in the past. Apart from early start-up, the other modes of prevention, such as mechanical methods (graded pressure stockings, intermittent pneumatic pressure) $[2,5,11,15-16]$ as well as pharmacological ones (low molecular weight heparins - LMWH) are recommended.

The choice of the method to prevent thromboembolic complications should be considered individually depending on the risk of thrombotic complications (Table 2).

Prophylactic treatment should be considered both after giving birth in a natural way and after caesarean delivery. It is particularly important in women with thrombophilia and in patients who have already experienced an episode of VTE. If there are at least two risk factors, such as obesity or age over 35 years,
Table I. Risk factors for venous thromboembolism

\begin{tabular}{|c|}
\hline Pre-existing risk factors \\
\hline Recurrent episodes of VTE in the past \\
\hline VTE with no obvious cause or history of use estrogen \\
\hline VTE related to the catchy cause \\
\hline Family history of VTE \\
\hline Known thrombophilia \\
\hline $\begin{array}{l}\text { Comorbidities, e.g. heart or lung diseases, systemic lupus, } \\
\text { cancer, inflammatory diseases, nephritic syndrome, sickle } \\
\text { cell disease, use of intravenous drug }\end{array}$ \\
\hline Age $>35$ years \\
\hline Obesity BMI > $30 \mathrm{~kg} / \mathrm{m}^{2}$ \\
\hline Pluriparity $\geq 3$ pregnancies \\
\hline Smoking tobacco \\
\hline Significant varicose veins \\
\hline Obstetric risk factors \\
\hline Preeclampsia \\
\hline $\begin{array}{l}\text { Dehydration/excessive vomiting/ovarian hyperstimulation } \\
\text { syndrome }\end{array}$ \\
\hline Multiple pregnancy or assisted reproduction \\
\hline Urgent caesarean section \\
\hline Efficient caesarean section \\
\hline Tick delivery \\
\hline Prolonged delivery $>24$ hours \\
\hline Perinatal haemorrhage $>\mathrm{I}$ I or the need for transfusion \\
\hline Transient risk factors \\
\hline General infection \\
\hline Immobilization \\
\hline Surgery during pregnancy or $<6^{\text {th }}$ week of confinement \\
\hline
\end{tabular}

Table 2. Risk groups depending on risk factors

\begin{tabular}{|c|c|c|}
\hline Risk groups & Definition & Preventive actions \\
\hline High risk & $\begin{array}{l}\text { Recurrent episodes of VTE in an interview } \\
(>\text { I episode) } \\
=\text { VTE with no obvious cause or related to use } \\
\text { estrogen } \\
\text { Single episode + thrombophilia or family history }\end{array}$ & $\begin{array}{l}\text { Recommended LMWH prevention during pregnancy } \\
\text { and in childbirth } \\
\text { Stockings of graduated pressure in pregnancy and } \\
\text { after childbirth }\end{array}$ \\
\hline $\begin{array}{l}\text { Moderate } \\
\text { risk }\end{array}$ & $\begin{array}{l}\geq 3 \text { risk factors other than those listed under the high } \\
\text { risk category } \\
\geq 2 \text { risk factors other than those listed in the high risk } \\
\text { category if the patient is hospitalized }\end{array}$ & $\begin{array}{l}\text { LMHH prophylaxis should be considered } \\
\text { Prophylaxis should be given after delivery for at least } \\
7 \text { days } \\
\text { Graded compression stockings should be considered } \\
\text { during pregnancy and confinement }\end{array}$ \\
\hline Low risk & $<3$ risk factors & $\begin{array}{l}\text { Early commissioning is recommended } \\
\text { Avoiding dehydration is recommended }\end{array}$ \\
\hline
\end{tabular}


anticoagulant prophylaxis and/or graded compression stockings should be considered for at least the duration of hospital stay $[3,5, \mathrm{I}$ I]. If multiple risk factors coexist, prophylaxis should also be considered after the patient has been discharged $[3,5, \mathrm{II}]$.

Preventive measures in women after natural childbirth and after caesarean section, which are not burdened with additional risk factors, should be limited to early start-up and proper hydration [5, I I].

It is also important to avoid long-term travel in a seated position. The preventive methods of VTE during the journey should include frequent activities such as stretching the lower leg muscles, and whole body stretching exercises, wearing loose clothing, avoiding dehydration. If the journey lasts for more than 8 hours, it is recommended to use knee-high socks with gradual pressure, providing $15-30 \mathrm{~mm} \mathrm{Hg}$ compression at the level of the ankle [5, I I].

The knowledge of pregnant women concerning risk and symptoms of VTE is very important, as it may help them to seek medical help quickly, and encourage them to take appropriate preventive measures.

Thus the goal of the present study was to investigate knowledge of pregnant or puerperal women about venous thromboembolism.

\section{Material and methods}

The method chosen for the study was the one of the diagnostic survey, the technique of polling with the use of a self-designed questionnaire, consisting of 20 closed questions, of which 13 concerned the topic of deep vein thrombosis (Fig. I). The remaining six questions referred to the age, place of residence, education, week of pregnancy, the number of pregnancies/lay-ups, constancy of gynaecologist's care. Questions I, 2, 8, I0, II, I 2 and I 3 use the conjunctive cafeteria method. In questions 4, 5, 6, 7, 8, I 4 it was possible to choose only one answer (disjunctive cafeteria). In the third question of the questionnaire, a five-point Likert scale was used.

The study was conducted within four months (from October 2017 to January 2018).

A mini pilot study was carried out among ten women during pregnancy and puerperium. The women surveyed did not make any comments, the questions were understandable.

The survey was conducted using Google Form, by providing a questionnaire on the Facebook social network website. The assumed average time of answering the questions was about 5 minutes. The selection of a random group was used in the work.

Two hundred and four questionnaires were qualified for the analysis.

\section{Results}

\section{Demographic data}

The most numerous age groups were respondents in the range of $26-35$ years $(63 \%$ [Cl 56.4, 69.6]) and I8-25 years $(31 \%$ [Cl 24.9, 37.5]).

The highest percentage of respondents were women with higher education $(71 \%[\mathrm{Cl} 64.5,76.9])$ and secondary education $(26 \%$ [Cl 20.4, 32.4]). The lowest $(3 \%$ [Cl I.44, 6.3]) - women with primary education.

The majority of women were in their first pregnancy or their first parturition $(56 \%$ [Cl $49.0,62.5])$. For $34 \%$ $[\mathrm{Cl} 27.7,40.6]$ of the respondents it was the second pregnancy or puerperium.

Almost all of the examined women (98\% [Cl 95.I, 99.2]) were under the constant care of a gynaecologist during pregnancy.

\section{Assessment of the knowledge of venous} thromboembolism among the studied women

The surveyed women were asked about the knowledge of diseases that may occur and are characteristic of pregnancy. Knowledge of venous thromboembolism was confirmed by less than $40.0 \%$ [Cl 33.7, 47.0] of respondents.

Women's knowledge about diseases that may occur during pregnancy did not come from medical personnel. When asked about "what possible diseases in pregnancy were you informed about by a gynaecologist/midwife/ nurse?", the women listed: maternal gestational diabetes TORCH and Rh incompatibility. Only $23.0 \%$ [Cl I7.8, 29.3] of the respondents received information about VTE. Worrying is the fact that a quarter of women declared that they did not receive information from medical staff about any of the diseases mentioned above.

Women were also asked a question about the most common cause of pregnancy-related deaths. Almost $39 \%$ [Cl $32.8,46 . \mathrm{I}]$ of women did not have knowledge on this subject, only about $36 \%$ [Cl 29.5, 42.6] of respondents correctly pointed to pulmonary embolism.

Unfortunately, only less than a quarter of women surveyed received the information about the risk of pregnant VTE from medical personnel.

Half of the women surveyed $(50.0 \%[\mathrm{Cl} 43.2$, 56.8]) declared that they were familiar with the specific term "venous thromboembolism". About 30\% of respondents learned about VTE from the Internet. Other sources of information were studies $(\mathrm{I} 6.7 \%[\mathrm{Cl}$ I 2.2, 22.4]), doctor (I3.7\% [CI 9.7, I9.1]) and friends/ /family (I $2.7 \%$ [Cl 8.8, I8.0]). Only about I I \% [Cl 7.2, 15.8] of the respondents obtained knowledge about VTE from a nurse or midwife (Fig. I). 


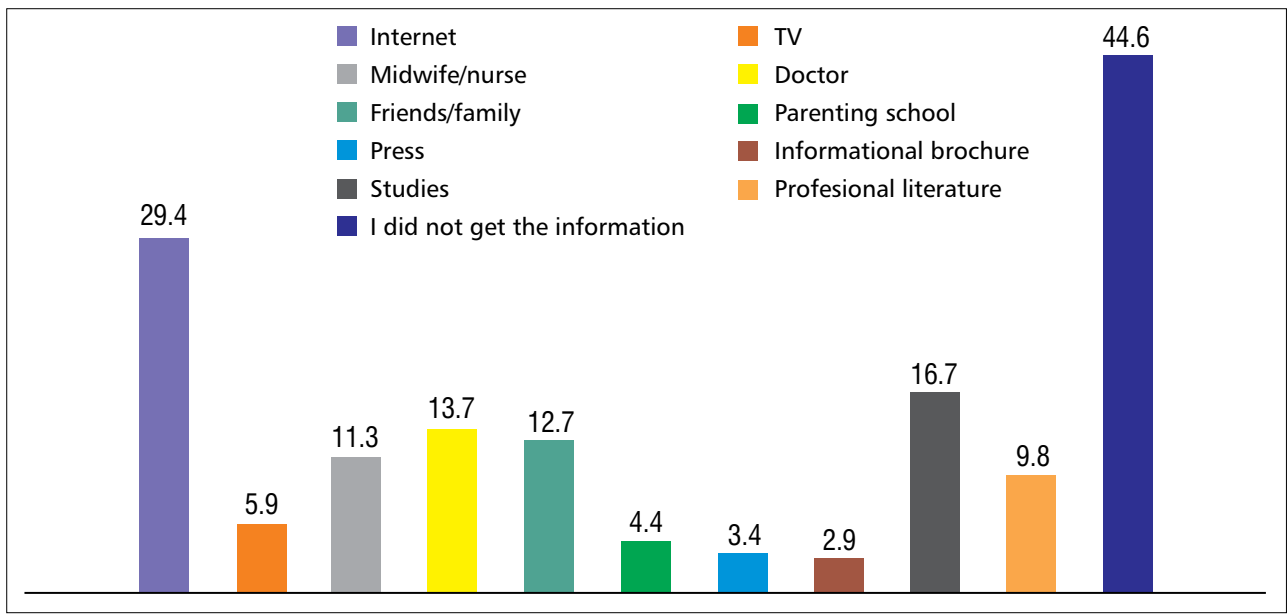

Figure I. Sources of the respondents' knowledge about venous thromboembolism (\%). *Percentages do not add up because the respondents had the opportunity to choose several answers

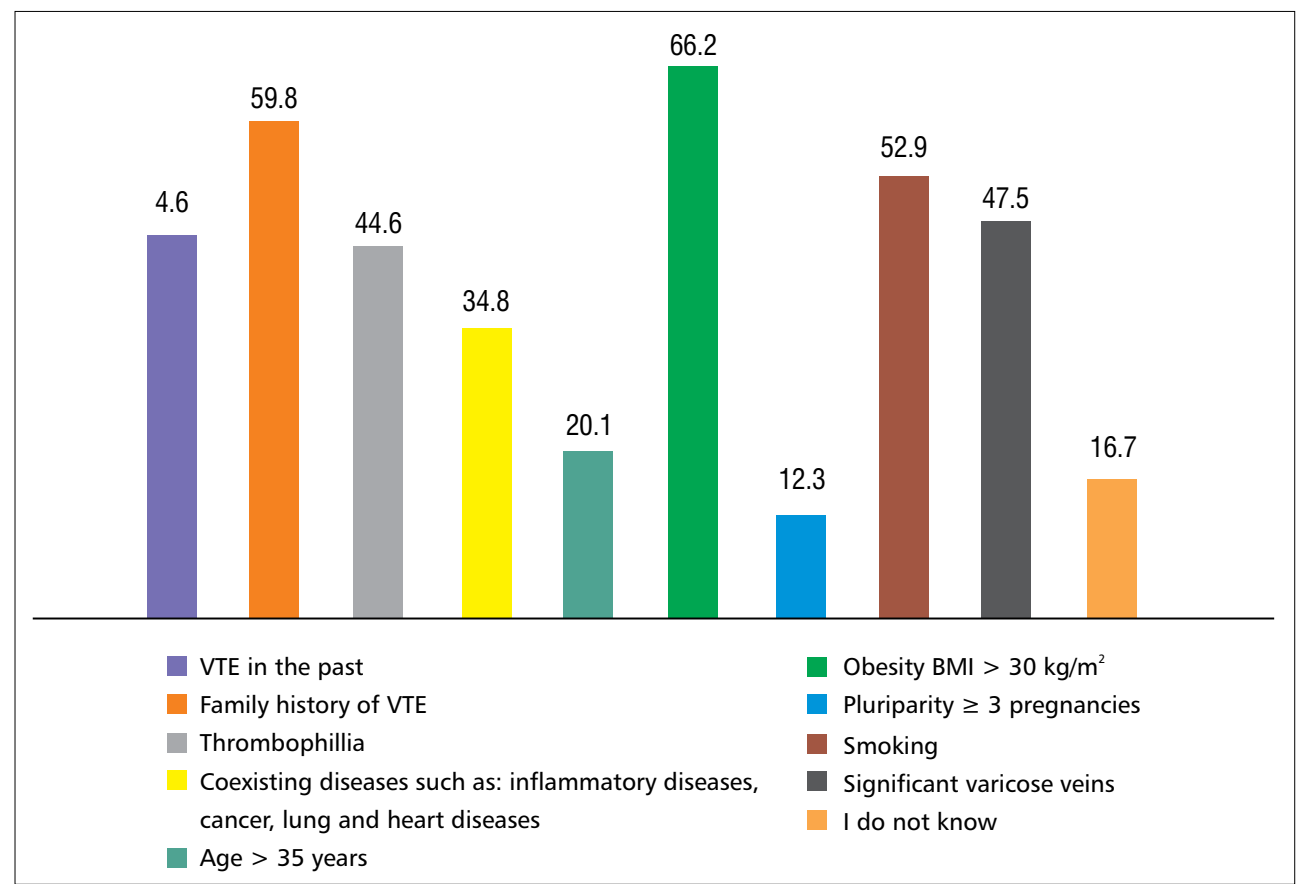

Figure 2. Knowledge about risk factors for venous thromboembolism among the studied women (\%). *Percentages do not add up because the respondents had the opportunity to choose several answers

\section{Assessment of knowledge of risk factors for venous thromboembolism among the studied women}

Over $60 \%[\mathrm{Cl} 53.0,66.3]$ of respondents correctly answered that pregnancy and puerperium increase the risk of VTE. However, $36 \%$ [Cl 29.5, 42.6] of women were unable to indicate the right answer to this question.
Almost 17\% [Cl 12.6, 22.9] of respondents admitted that they did not know any risk factor for VTE (Fig. 2).

Respondents asked about obstetric risk factors for venous thromboembolic disease most frequently indicated immobilisation (47.5\% [Cl 40.8, 54.4]. Slightly fewer respondents indicated surgery $(24.5 \%[\mathrm{Cl} 19.1$, $30.8]$ ) or caesarean section $(27 \%$ [Cl 2I.3, 33.4]). Al- 


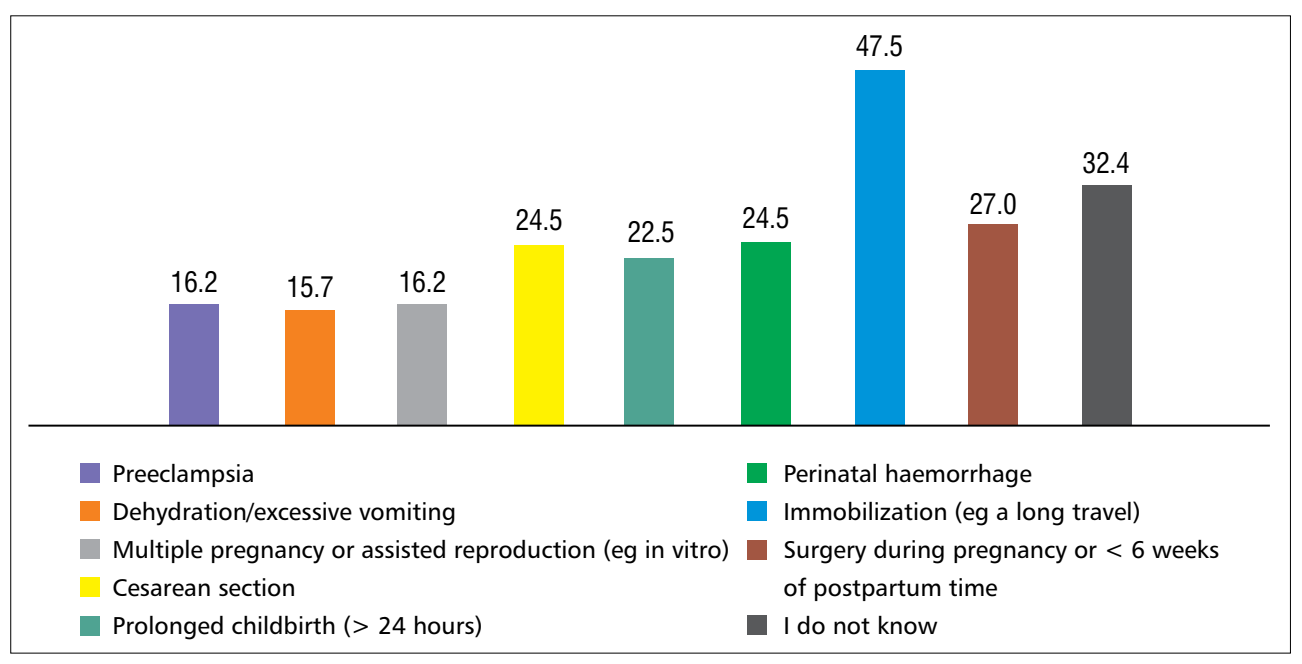

Figure 3. Knowledge of respondents about pregnancy and puerperal related risk of VTE (\%). * Percentages do not add up because the respondents had the opportunity to choose several answers

most $\mathrm{I} / 3$ of surveyed women didn't know any obstetric VTE risk factors (32.4\% [Cl 26.3, 39.0]) (Fig. 3).

\section{Assessment of knowledge about the symptoms of venous thromboembolism among the studied women}

Due to the change in the colour of the skin of one leg, medical assistance would be sought by $3 / 4$ women

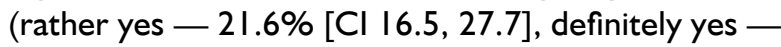
$53.9 \%[\mathrm{Cl} 47 . \mathrm{I}, 60.6])$. A swelling of one leg would induce half of the women surveyed to report to the doctor and calf pain only about $13 \%[\mathrm{Cl} 9.3,18.6]$. Dyspnoea and cough for just over half of the respondents would be disturbing enough to go to the doctor immediately.

More than $70 \%[\mathrm{Cl} 63.5,76.0]$ of respondents correctly indicated that pain, swelling, redness of one limb are symptoms that may signal deep vein thrombosis. Less than $50 \%$ [Cl 43.2, 56.8] of the respondents indicated tenderness or painfulness of the limb. Only about one third of the surveyed women pointed to limb warming $(33.3 \%[\mathrm{Cl} 27.2,40.1])$ and enlargement of superficial veins of the limb $(30.4 \%[\mathrm{Cl} 24.5,37.0])$. Almost half of the respondents incorrectly identified pain and swelling of both legs with deep vein thrombosis. Just over $20 \%$ [Cl I5.2, 26.I] of respondents admitted that they did not know any symptoms of this disease (Fig. 4).

Symptoms indicative of pulmonary embolism include dyspnoea, tachypnoea, chest pain increasing during inspiration, cough, haemoptysis and collapse. Over $70 \%$ of respondents correctly indicated dyspnoea $(72.5 \%$ [Cl 66.I, 78.2]) and pleural pain, increasing during inspiration $(73.5 \%[\mathrm{Cl} 67.1,79.1])$. Worrying is that to a much lesser extent women indicated other equally important symptoms of pulmonary embolism, such as tachypnoea (4I.7\% [Cl 35.I , 48.5]) or haemoptysis (I2.3\% [Cl 8.4, I7.5]) (Fig. 5).

\section{Assessment of knowledge on the principles of prevention of venous thromboembolism among the studied women}

Most women (95\% [Cl 9l.2, 97.3]) correctly identified the need for proper hydration. Women often chose answers such as tobacco abstinence $(94.5 \%$ [Cl 90.6, $97.0])$ or maintaining normal body mass $(90.7 \%[\mathrm{Cl}$ $85.9,94.0]$ ). It is astonishing to note that definitely fewer respondents indicated relaxing of calf muscles $(64.2 \%$ [Cl 57.4, 70.5]), wearing graduated bracing knee socks $(50 \%[\mathrm{Cl} 43.2,56.8])$ or heparin injection $(56 \%[\mathrm{Cl} 49.0$, 62.5]). Unfortunately, II\% [Cl 7.2, I5.8] of pregnant or puerperium women think they should consume alcohol in moderate amounts to prevent VTE.

\section{Discussion}

In the course of our study, women's knowledge regarding venous thromboembolism during pregnancy and confinement was analysed. Unfortunately only half of the women surveyed reported that they were familiar with the term "venous thromboembolism". The importance of our findings is reflected in potential consequences of those knowledge deficits, because pulmonary embolism is still the leading cause of death among pregnant women and puerperium $[1-5]$ and the incidence of venous thromboembolic disease among pregnant women is much higher than in a comparable non-pregnant age group [I-7]. 


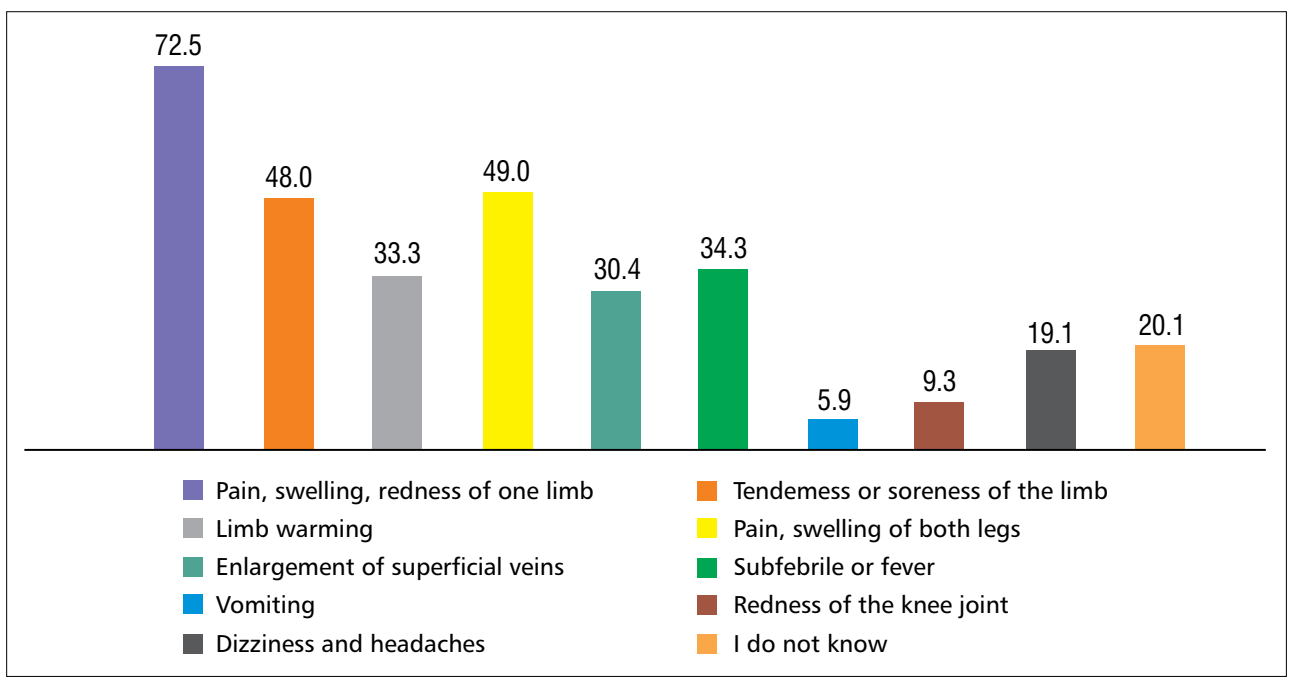

Figure 4. Symptoms of deep vein thrombosis in the respondents' opinion (\%). * Percentages do not add up because the respondents had the opportunity to choose several answers

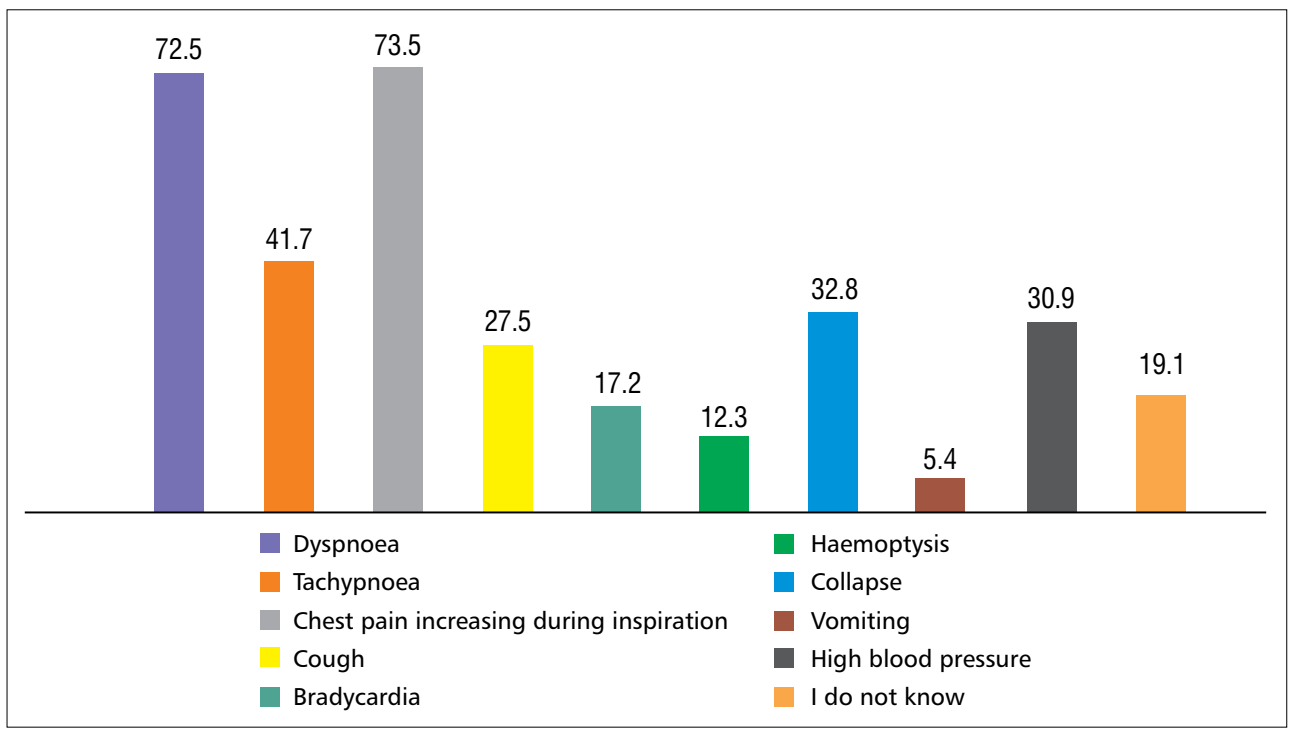

Figure 5. Symptoms of pulmonary embolism in the respondents' opinion (\%). *Percentages do not add up because the respondents had the opportunity to choose several answers

Although $63 \%$ of respondents correctly answered that pregnancy and puerperium increase the risk of VTE, less than half of women could point to specific pregnancy and puerperium situations that increase the risk of disease.

The results of our study were similar to those obtained in the study by Mellon et al. who investigated awareness of pregnancy-associated health risks among pregnant women and male partners and showed significant knowledge deficiencies concerning common and serious health hazards associated with pregnancy [17].
Because of great deficiencies in knowledge of symptoms, risk factors and methods of prevention of venous thromboembolism, a special emphasis in education should be placed on these issues.

Public health campaigns could help increase awareness about the wide range of pregnancy-associated health conditions among pregnant woman and puerperium. It is worrying that only about II\% of the respondents obtained knowledge about VTE from a nurse or midwife, who are trained to educate patients. 
Given the fact, that currently the Internet is the basic source of knowledge, especially for young people, it is worth paying attention to the reliability of information contained therein. At the same time, the Internet, due to its availability, should be used by professionals to improve knowledge not only about VTE but also other diseases of great epidemiological importance.

\section{Conclusions}

The incidence of venous thromboembolic disease among pregnant women is much higher than in a comparable non-pregnant age group and pulmonary embolism is the leading cause of death among pregnant women and puerperium.

Unfortunately, women's knowledge of venous thromboembolism was insufficient and currently the most common source of information not only for pregnant women is the Internet.

\section{Conflict of interest}

None.

\section{References:}

I. Konstantinides SV, Torbicki A, Agnelli G, et al. Task Force for the Diagnosis and Management of Acute Pulmonary Embolism of the European Society of Cardiology (ESC). 2014 ESC guidelines on the diagnosis and management of acute pulmonary embolism. Eur Heart J. 2014; 35(43): 3033-69, 3069a, doi: 10.1093/ eurheartj/ehu283, indexed in Pubmed: 25173341.

2. Regitz-Zagrosek V, Lundqvist CB, Borghi C, et al. ESC Guidelines on the management of cardiovascular diseases during pregnancy: The Task Force on the Management of Cardiovascular Diseases during Pregnancy of the European Society of Cardiology (ESC). Eur Heart J. 20 I ; 32(24): 3147-3197, doi: 10.1093/ eurheartj/ehr218.

3. Marik PE, Plante LA. Venous thromboembolic disease and pregnancy. N Engl J Med. 2008; 359(19): 2025-2033, doi: 10.1056/ NEJMra0707993, indexed in Pubmed: 18987370.

4. Sullivan EA, Ford JB, Chambers G, et al. Maternal mortality in Australia, 1973-1996. Aust N ZJ Obstet Gynaecol. 2004; 44(5): 452-7; discussion 377, doi: 10.1 I I I/j. 1479-828X.2004.003 I3.x, indexed in Pubmed: 15387869.

5. Tomkowski W, Kuca P, Urbanek T, et al. Venous thromboembolism - recommendations on the prevention, diagnostic approach and management. The 2017 Polish Consensus Statement. Acta Angiologica. 2017; 23(2): 35-7I, doi: 10.5603/aa.2017.0008.

6. James AH, Tapson VF, Goldhaber SZ. Thrombosis during pregnancy and the postpartum period. Am J Obstet Gynecol. 2005;
193(I): 216-219, doi: 10.1016/j.ajog.2004.11.037, indexed in Pubmed: 16021082

7. Heit JA, Kobbervig CE, James AH, et al. Trends in the incidence of venous thromboembolism during pregnancy or postpartum: a 30-year population-based study. Ann Intern Med. 2005; |43(I0): 697-706, doi: |0.7326/0003-48| |9-|43-|0-2005 | | I5000006, indexed in Pubmed: 16287790.

8. Blanco-Molina Á, Trujillo-Santos J, Pesavento R, et al. RIETE Investigators, RIETE Investigators, RIETE Investigators, RIETE Investigators. Venous thromboembolism during pregnancy or postpartum: findings from the RIETE Registry. Thromb Haemost. 2007; 97(2): 186-190, indexed in Pubmed: 17264945.

9. Barco S, Nijkeuter M, Middeldorp S. Pregnancy and venous thromboembolism. Semin Thromb Hemost. 2013; 39(5): 549-558, doi: 10.1055/s-0033-1343893, indexed in Pubmed: 23633191 .

10. Liu S, Rouleau J, Joseph KS, et al. Epidemiology of Pregnancy-associated Venous Thromboembolism: A Population-based Study in Canada. Journal of Obstetrics and Gynaecology Canada. 2009; 3I(7): 6II-620, doi: 10.1016/s I70I-2163(16)34240-2.

II. Royal College of Obstetricians and Gynaecologists. Reducing the Risk of Thrombosis And Embolism During Pregnancy and the Puerperium. Green-top Guideline 2009; 37a.

12. O'Connor DJ, Scher LA, Gargiulo NJ, et al. Incidence and characteristics of venous thromboembolic disease during pregnancy and the postnatal period: a contemporary series. Ann Vasc Surg. 20I I; 25(I): 9-14, doi: 10.1016/j.avsg.2010.04.003, indexed in Pubmed: 20800436.

13. Rutherford SE, Phelan JP. Deep venous thrombosis and pulmonary embolism in pregnancy. Obstet Gynecol Clin North Am. 1991; 18(2): 345-370, indexed in Pubmed: 1945260.

14. Nijkeuter M, Ginsberg JS, Huisman MV. Diagnosis of deep vein thrombosis and pulmonary embolism in pregnancy: a systematic review. J Thromb Haemost. 2006; 4(3): 496-500, doi: 10.1 I I I/j.1538-7836.2005.01779.x, indexed in Pubmed: 16405518

15. Bauersachs RM, Dudenhausen J, Faridi A, et al. EThIG Investigators. Risk stratification and heparin prophylaxis to prevent venous thromboembolism in pregnant women. Thromb Haemost. 2007; 98(6): 1237-1245, doi: 10.1 160/th07-05-0329, indexed in Pubmed: 18064320.

16. Greer IA, Nelson-Piercy C. Low-molecular-weight heparins for thromboprophylaxis and treatment of venous thromboembolism in pregnancy: a systematic review of safety and efficacy. Blood. 2005; 106(2): 40I-407, doi: 10.1 I82/blood-2005-02-0626, indexed in Pubmed: $158 \mid 1953$.

17. Mellon M, Schiller A, Nelson AL, et al. Awareness of Pregnancy-Associated Health Risks Among Pregnant Women and Male Partners Surveyed in a Prenatal Clinic. J Womens Health (Larchmt). 2020; 29(3): 376-382, doi: 10.1089/jwh.2018.7585, indexed in Pubmed: 31647358. 